\title{
The Analysis of the Central Theme in Wolfe Novel of "Say Yes"
}

\author{
Ke YAN \\ Nanyang Medical College \\ Nanyang,473058 China
}

\begin{abstract}
American writer Tobias Wolfe's short story "Say Yes", the Chinese translation is "say yes", the surface is about everyday dispute between a husband and wife, but the theme of the work has nothing to do with the marital relationship. In this paper, with the creative works and cultural background, through reading novels, it is to analyze the theme of the novel. This paper argues that the theme of this work is to expose the hidden racism in American society that is a new existence.
\end{abstract}

\section{Keywords-Subject; Text Theme ; "Say Yes"}

\section{A THEME AND ITS MANIFESTATIONS}

The theme is literature displayed image system by the central idea and the dominant mood, which is closely associated with the text in the text. The topic is the potential, it is hidden in the depths of the image of the system, not on the actual space occupied by the text, but it must always been prominent in the center of the main theme. It is unlikely to allow the phenomenon of alienation from it, the phenomenon must be under its shadow, reflecting the common characteristics of ideographic (Zhang Yonggang - Edited, 2001: 92) the characteristics of the decision. The understanding of the subject depends on the interpretation of the text that must be those common features extracted ideographic theme works from the text. In addition to the interpretation of the text than to analyze literary themes, it noted the following three points: First, is to understand the cultural background of the works produced, the second is to understand the author's life and thought. The authors note that the creation of the three themes (Li Ping. , 1990), of course, cultural background and personal mood reconstruction or creation are also the author in an absolute sense when only the best state is difficult to fully achieve in reality. This paper combines the novel "say yes" cultural background, through the interpretation of the text, especially in the analysis of the role of the husband of the text, to interpret the theme of the novel.

\section{II. "SAY Yes" the MAIN CONTENT AND CREATIVE BACKGROUND}

The author of the "Say Yes" is a famous contemporary American writer Tobias Wolfe. Novel is about the friction between a pair of white couple married whites and blacks around the appropriateness of the topic and the resulting series of dialogues. The novel is about a couple washing dishes while chatting at the beginning. They talked about the issues she spoke to blacks and a white, the husband believes that for the overall consideration, blacks and whites to marry is never a good idea. The couple embarked on a series of two conversations. Assuming he is black wife, he asked her husband he would be willing to marry her after some evasive excuses, husband and wife had confided really pressing harder and harder: He will not marry her wife for this Answer satisfaction, angrily away. Husband is very depressed; all the housework is done silently, carrying trash out of the house. In the quiet of the stars, he recalled the years of their marriage, the couple are harmonious and happy, for his performance that night he was very upset, he came home and told his wife he wanted to marry her wife who are toilet flushing, asking him to turn off the lights to go to bed waiting for her. As a result, in the dark, he heard some noise, he sat up in bed, heart pounding, I feel a stranger in the room to move around.

On the surface, the story is very much like the couple because his wife was too immature and too headstrong odds. They got married for three years, the couple relationship is harmonious, but his wife was like a naive little girl pressed her husband as a very silly question, her husband answered that she is not satisfied. she would get angry, turning our backs to ignore him, until her husband came to coax her husband and looks very simple - very frank, honest and even a little too inflexible, but the man intends to please wife, therefore it is a "considerate husband." However, the theme in ingredient combination works Contacts cultural background of its creation, which goes to analyze the details of the text, you will not find on the theme that looks like the surface of the work.

Theme ingredient refers to helping unfolding and the formation of a recurring theme of text structure or literary comparison means. "Say yes" theme ingredient is the issue of blacks and whites to marry husband oppose such a marriage on the grounds that different black and white background, cannot reach each other really understand the point. Therefore, the study creative works with the theme ingredient relevant social and cultural background to help interpret the theme of the text, while the essence of the theme ingredient is race.

"Say yes" was first published in 1985, which is half of the 20th century, when American society of racism model has undergone great changes. In the half of last century, the United States prevailed in society based on apartheid racism, also known as Jim - Crow racism. This is a blatant racism, 
which is characterized in education - health - in all aspects of social life, housing and other non-blacks and whites mixing. From the beginning of the second half of the 20th century, this decline of racism increasingly is replaced by negative a new form of racism - racism inaction in this new form of racism mode, there were the majority of white racial equality and recognition integration, but inter-ethnic marriages are still not universally recognized. To 1983, more than 50 percent of whites negative had attitude of miscegenation. (Jinshan Hu, 2004) and in the new forms of racism, there is an important mode of expression, that is, whites generally hold a negative view against blacks. In this look under the social and cultural background, in the "say yes" the text, the theme of the work seems amazing.

\section{THEME ANALYSIS OF "SAY YES"}

If you say that "say yes" is the theme of the above expression of the relationship between husband and wife, or views an attitude. Then we will find that there have been many conflicting between local phenomenon used to express the theme of the works; and literature phenomenon must work under the shadow of the theme, reflecting the common characteristics of ideographic. These contradictions remind us that the work should be another topic. These conflicting interpretation of the text was to explore the phenomenon of topics provide a breakthrough. Works of these phenomena are happening around her husband's role. For example, a husband posed a good husband; one of its manifestations is actively helping his wife to do the housework. The second is for the first time of his wife's hand was cut rushed into action to take measures, the third is with his wife on black when the Cold War initiative bow on a white wedding issue summation to accommodate wife. These points of view alone, her husband is indeed a good husband but in the text of the added number of additional details that will make the reader question the image of this thoughtful example: his wife will sometimes brow locking lip biting. When he saw his wife pair of facial expressions when he knew he had better shut up, but he never had done. In fact, this expression actually stimulates more words, he said. Again, his wife heard him who say only blacks and whites after a bad marriage are asked a "why" that did not say anything else, he said: "Listen, I have a black school students, working in units and having black employees, and we have been at peace. I do not need me now to imply a racist. "

"I'm alluding to anything," she said. "I just do not know what is wrong for blacks to get married with whites" Angry husband gets so easy, so easy to accuse his wife for no reason, it is difficult as "thoughtful," but he thinks it is a very "thoughtful" husband. From here, the husband "hypocritical" features are exposed.

It is mentioned above that the phenomenon of literary works must reflect the common features of ideographic. Therefore, the writer gives the husband the role of "hypocrisy" feature, this feature is bound to consistently reflect in image-building aspects of the role. In other words, this role may be inconsistencies between the self-proclaimed and objective presence in other areas.
The main part of the work is two couples who are saying something about blacks and whites. It is around the topic of conversation. Wife asked why blacks and whites to marry are bad. She did not mention any words related to racism. But her husband is very sensitive, and he immediately said, you listen, I have a black school students, working in units and having black employees, and we have been at peace. I do not need you now to come to insinuate I'm a racist. Wife declared that she just wanted to why he had such a idea. Reason for her husband in the following section come out in conversation: "They had different cultures, hey, they even have their own language, of course if it is a language, I like to listen to their talk..." "But you do not marry to a black man, right?"She asked.

"But that's not the same thing. They have different culture and they can never really understand each other." "It's like you know me?" His wife asked. "Yeah, like I know you." As it can be seen from the above, the husband does not think of himself as racist, and extremely sensitive to racism label. He insisted that he non-racist

The reason was, "I go to school that has a black student, the unit of work has black employees, and we have been at peace." However, he is also not in favor of blacks and whites to marry on the grounds that they come from different cultures, it is impossible to reach mutual understanding between husband and wife. It seems her husband, which shared the same school of social resources and work units with the same black and black. Wedding is very different; the former is acceptable, even if the latter does not mean you do not accept that is racist. And as mentioned earlier, it is accepted in education - employment and other aspects of racial integration, recognition and blacks the same school the reasonableness of the same work unit, indicating that the husband does not agree with the apartheid regime, he is not a Jim / Crow-style race advocator. This is an improvement relative to the first half of the 20th century, a lot of white support for apartheid. However, her husband also believed in my heart, "black and white are different". Therefore, it does not recognize marriages between blacks and whites, this is precisely the performance of the 20th century, a new form of the second half of the start of the new racism is more subtle racism - more subtle, and its refusal is to recognize the core performance that is one of the blacks and whites

As regard between people are essentially communicating but emphasizing the difference between the two. Under the influence of this new racism of whites, they do not see or do not believe that black people are like them- friendly aggressive - full of dreams and they are willing to fight for a dream with so positive side. They think always black have negative image, such as lazy - dishonest - stealing. (Jinshan $\mathrm{Hu}, 2004)$ In this short story, the husband did not use such words to describe black people, but he repeatedly referred to blacks and whites they are "different." However, this mild "difference" has just exposed his new racist tendencies.

Then, his wife is to put the question of marriage between white and black personally. She assumed that she is black, and asked if her husband would marry her.

"This issue is totally ridiculous. If you were black, then we probably would not have met. The only one I know black 
girls be debating club is my partner." "But suppose we met, and I was a Negro? "" That you could probably date with a black person. "He picked up the watering can spray silverware.

"If I was black, there is no love, and we love each other."

He glanced at her. She was looking at him, his eyes shining. "You see," he said, with a rational tone, "this issue is very stupid. If you are black you are not you."

Wife requested her husband "We just talk." Her husband told her that if they get married, "the late life will regret in life," he finally admitted that if she was black, he has the least willing to marry her. After listening that, his wife angrily got away.

There are still two people, just the wife changed the color, and the husband would think they might have little happy marriage, which is in the final analysis. or because he thought black people arelike with the self, he may have few people who has the same IQ, temperament, habits, the ability to make her self-person like his wife. To put it bluntly, his heart is still discrimination against blacks. This is again linked to him and racism.

Ironically, in the end of the article, he decided to get well with his wife, and told her he was willing to marry her. Wife let him put out the light and wait for her.

He reached hand to pull cord of the headlight lamp, and the room was dark. "Okay." He said. He lay there, but nothing had happened. "Okay." He added. Then he heard a movement room. He sat up, but could not see anything. The room was silent. His heart pounded jumped, as did the first jump of the night they spent together; and now his heart is still such a jump, that is, when he heard movement in the darkness, waiting and listening again - someone is walking in the room sound with a stranger's voice.

Even though he and his wife are whites, even if his heart is convinced that he and his wife are so mutual understanding, but his wife's every night activities will wake him cool, as long as he saw little in the dark to his wife, he would think she is a "stranger." This is a wonderful satire based on the color difference that is believed blacks and whites are different, it again prompted theme works independent of the marital relationship, but to expose the new forms of racism.

\section{CONCLUSION}

This article referred to novel "say yes" with the interpretation of the text related to the background; it is the themes analysis. This paper considers the works by shaping the hypocrisy, small deeds husband consistent image, is to expose and criticize the American society of new forms of covert racism. Theme of the works is much than the husband and wife relationship.

\section{Reference}

[1] Zhang Yonggang, Edited by: "Literary Theory", Peking University Press, 2001 edition

[2] Little JW Teacher development and educational policy In Michael Fullan \& Andy.Hargreaves (Dds), Teacher development and educational change London \& Washington DC:... Falmer Press, 1992.170.

[3] Pennington, MC A Professional Development Focus for the Language Teaching Practicum [A] In JCRichards and D. Nunan (Eds.) Second Language Teacher Education [C] New York: Cambridge UniversityPress, 1990: 17.

[4] Hu Jinshan: "After the United States since the 20th century, people Racial Attitudes change half of", "Xiamen University" (Philosophy and Social Sciences), 20042

[5] Li Ping: "fuzziness On the theme of literary works", "Zhejiang Journal", 19903

[6] Hoyle. E. Professionalizatiion and deprofessionalization in education. In Eric Hoyle and JacquettaMegarry (Eds). World yearbook of education 1980: Professional development of teachers London: KoganPage, 1980: 42.

[7] Perry P. Professional Development: the inspectorate in England and Wales [M]. In EricHoyle andacquetta Megarry (Eds), world yearbook of education 1980: Profession development of teachers, London: Kogan Page, 1980: 143.

[8] Penny, U A Course in Language Teaching:.. Practice and Theory [M] Beijing: Foreign Language Teaching and Research Press, 2000. 